\title{
OPEN Analysing the distance decay of community similarity in river networks using Bayesian methods
}

\author{
Filipe S. Dias ${ }^{1,2,3 凶}$, Michael Betancourt ${ }^{4}$, Patricia María Rodríguez-González $^{5}$ \& \\ Luís Borda-de-Água ${ }^{1,2,3}$
}

The distance decay of community similarity (DDCS) is a pattern that is widely observed in terrestrial and aquatic environments. Niche-based theories argue that species are sorted in space according to their ability to adapt to new environmental conditions. The ecological neutral theory argues that community similarity decays due to ecological drift. The continuum hypothesis provides an intermediate perspective between niche-based theories and the neutral theory, arguing that niche and neutral factors are at the opposite ends of a continuum that ranges from competitive to stochastic exclusion. We assessed the association between niche-based and neutral factors and changes in community similarity measured by Sorensen's index in riparian plant communities. We assessed the importance of neutral processes using network distances and flow connection and of niche-based processes using Strahler order differences and precipitation differences. We used a hierarchical Bayesian approach to determine which perspective is best supported by the results. We used dataset composed of 338 vegetation censuses from eleven river basins in continental Portugal. We observed that changes in Sorensen indices were associated with network distance, flow connection, Strahler order difference and precipitation difference but to different degrees. The results suggest that community similarity changes are associated with environmental and neutral factors, supporting the continuum hypothesis.

The distance decay of community similarity (DDCS) states that geographically close communities tend to be more similar than those that are further apart ${ }^{1,2}$. The DDCS is implicit in several ecological phenomena such as species turnover along environmental gradients ${ }^{3}$, source-sink dynamics ${ }^{4,5}$, metapopulations ${ }^{6}$, and the theory of island biogeography ${ }^{7}$. There are three major perspectives or hypothesis for explaining this ecological pattern ${ }^{2,8,9}$. Niche-based theories argue that as environmental conditions change, species are sorted according to their ability to adapt to new conditions and habitats ${ }^{10,11}$. The ecological neutral theory ${ }^{12}$ argues that community similarity decays due to ecological stochasticity, caused by random births and deaths in a population (i.e., ecological drift) ${ }^{13}$, random dispersal, and dispersal limitation. The continuum hypothesis provides an intermediate perspective, arguing that niche and neutral factors are, in fact, at the opposite ends of a continuum that ranges from competitive exclusion to stochastic exclusion ${ }^{14}$. Understanding the ecological mechanisms that underpin the DDCS is crucial for analysing changes in community composition and for correctly identifying the impacts of anthropogenic activities, climate change and for developing effective conservation plans ${ }^{15,16}$.

The first studies on the distance decay of community similarity date from the 1960s but it was Nekola and White ${ }^{1}$ who laid the foundations for using distance decay rates to describe, compare, and understand biodiversity patterns ${ }^{17}$. The authors examined distance decay rates in vascular plants and bryophytes of boreal and montane spruce-fir forests in North America and observed negative exponential decay rates. More importantly, they observed that decay rates varied between vascular plants and bryophytes, with growth forms, between dispersal methods, and at different scales. Subsequent studies built on this framework by adding the analysis of how changes in environmental conditions affect community similarity ${ }^{2,18,19}$.

\footnotetext{
${ }^{1} \mathrm{CIBIO} /$ InBio, Centro de Investigação em Biodiversidade e Recursos Genéticos, Laboratório Associado, Universidade do Porto, Campus Agrário de Vairão, 4485-661 Vairão, Portugal. ${ }^{2} \mathrm{CIBIO} / \mathrm{InBio}$, Centro de Investigação em Biodiversidade e Recursos Genéticos, Laboratório Associado, Instituto Superior de Agronomia, Universidade de Lisboa, Tapada da Ajuda, 1349-017 Lisbon, Portugal. ${ }^{3}$ BIOPOLIS Program in Genomics, Biodiversity and Land Planning, CIBIO, Campus de Vairão, 4485-661 Vairão, Portugal. ${ }^{4}$ Symplectomorphic, LLC., New York, USA. ${ }^{5}$ Centro de Estudos Florestais, Instituto Superior de Agronomia, Universidade de Lisboa, Tapada da Ajuda, 1349-017 Lisbon, Portugal. ${ }^{\varpi}$ email: filipesdias@gmail.com
} 


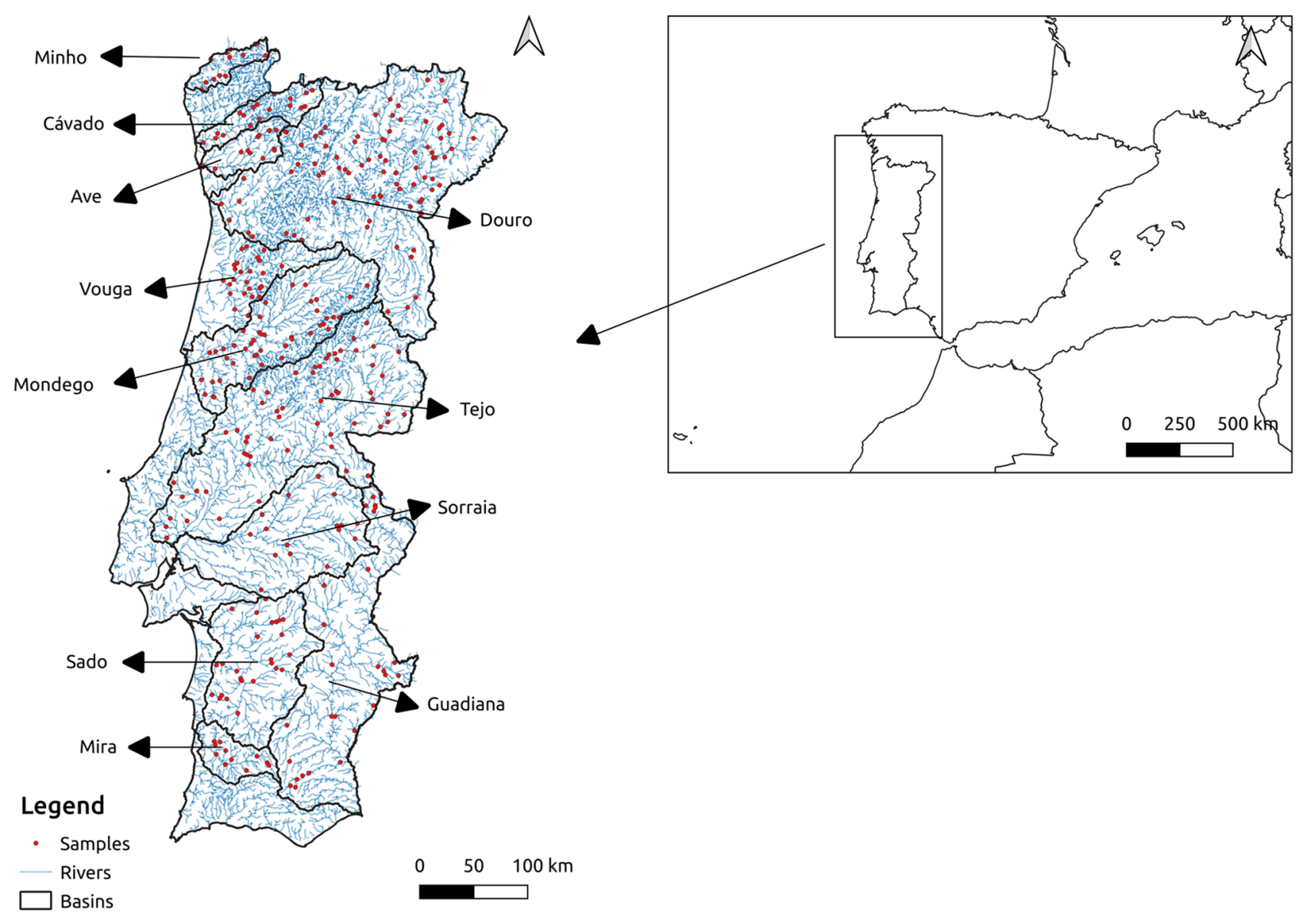

Figure 1. Continental Portugal and the location of the vegetation plots in the eleven river basins studied (red dots). This figure was created with QGIS $3 \cdot 20.3^{63}$.

Riverine ecosystems support extremely high levels of biodiversity and provide key ecosystem services ${ }^{20,21}$. So far, few studies analysed the DDCS in riparian plant communities and the results are disparate. For instance, Rouquette et al. ${ }^{22}$ studied an urban river network in the UK and found no significant association between Euclidean, network and flow distance and changes in plant community similarity after accounting for environmental differences. In Toronto, Canada, Kuglerová et al. ${ }^{23}$ studied riparian vegetation in seven river basins and found that after accounting for environmental differences, the distance was only a significant predictor for community composition changes in three out of seven basins. Finally, in China, Zhang et al. ${ }^{24}$ studied aquatic macrophytes in a large river basin and concluded that community similarity changes were significantly associated with distance, even after accounting for environmental covariates. Despite these studies, there is still little data on the relative importance of niche-based factors and neutral factors, which are crucial to understand structure and community assembly processes in riverine ecosystems.

In this study, we analysed the factors that are associated with the DDCS in riparian plant communities. Specifically, we aimed to assess the effect of niche and neutral factors on community similarity as measured by the Sorensen's index ${ }^{25}$. We selected two covariates that we considered predominately neutral (network distance and flow connection) and two covariates that we considered predominately niche-based (precipitation difference and Strahler order difference). We ensured that both neutral and niche-based covariates had low pairwise correlations. Despite the careful selection process, the neutral/niche-based covariates may be correlated with unmeasured niche-based factors/neutral covariates, therefore we cannot assume a one to one relationship between each covariate and the corresponding factors. We fit a model with these four covariates and assessed the relative support for the neutral theory, niche-based theories and the continuum hypothesis based on the association between the covariates and Sorensen indices. We expected to find that both neutral and niche-based would to some extent be associated with changes in community similarity.

\section{Methods}

Study area. This study took place in mainland Portugal, southwestern Europe, between $37^{\circ}$ and $42^{\circ} \mathrm{N}$ (Fig. 1). The northern half is hilly, with $95 \%$ of the area above $400 \mathrm{~m}$, while the south is flatter, with $62 \%$ of the area below $200 \mathrm{~m}$. The climate ranges between Temperate in the North and Mediterranean in central and southern Portugal and presents a significant climatic and altitudinal gradient ${ }^{26}$. In general, temperature increases and precipitation decreases when moving from north to south and west to east. Mean annual temperatures range between $7^{\circ} \mathrm{C}$ in the mountains of central Portugal and $18^{\circ} \mathrm{C}$ in the southern coastal region. The highest mean 


\begin{tabular}{|l|l|l|}
\hline Classification & Variable & Description and units \\
\hline \multirow{2}{*}{ Neutral } & Network distance & Network distance between a pair of vegetation samples $(\mathrm{km})$ \\
\cline { 2 - 3 } & Flow connection & 1-samples are flow connected, 0-samples are not flow connected \\
\hline \multirow{2}{*}{ Niche-based } & Strahler order difference & Strahler order difference between the pair of vegetation samples \\
\cline { 2 - 3 } & Precipitation difference & Difference in annual precipitation between the pair of vegetation samples \\
\hline
\end{tabular}

Table 1. List of neutral and niche-based variables included in the model developed to assess the relative importance of both neutral and niche-based factors for explaining changes in community similarity measured by Sorensen's index.

annual precipitation occurs along the highlands in the northwestern region (>3000 $\mathrm{mm} /$ year) and the lowest along the southern coast and the eastern part of the territory (below or around $500 \mathrm{~mm}$ ). On average, about $42 \%$ of the annual precipitation falls during the winter season (December-February), and only 6\% during Summer (June-August) ${ }^{27}$.

Data collection and processing. The vegetation data were collected between 2003 and 2006 in 404 sites across 38 river basins in continental Portugal during the pre-assessment surveys conducted to implement the Water Framework Directive (WFD) ${ }^{28-30}$. Field surveys followed the protocol defined for the WFD implementation $^{29}$, which involved establishing a 100 -m plot along the fluvial corridor with a width corresponding to regular floods in each site and all plant species were identified. In smaller rivers plot sizes were smaller and in larger rivers plot sizes were larger, which ensured we obtained a representative sample of the community. Plots were evenly distributed across the river basin to maximize coverage. No plant specimens were collected or damaged during fieldwork.

For this study, we selected the 11 largest river basins, which were the ones for which there were at least ten vegetation surveys. For the remaining 26 river basins, there were only 3-5 surveys each which we considered insufficient for carrying out this study.

We calculated the Sorensen similarity index between pairs of sites within the same river basin with:

$$
\text { Sorensen index }=2 \mathrm{a} / 2 \mathrm{a}+\mathrm{b}+\mathrm{c}
$$

where $a$ is the number of species in common between both sites, $b$ is the number of unique species on the first site, and $c$ is the number of unique species on the second site. Therefore, the Sorensen index is the number of species in common between two sites divided by their average number of species. An index value of 1 indicates that communities have the same species composition, while 0 indicates that communities share zero species. We ran calculations with the package "vegan 2.57 "31 using $\mathrm{R} 4.0 .4^{32}$.

We followed a careful selection process for choosing neutral and niche-based covariates (Table 1). We started by considering differences in distance (Euclidean, network and flow), in climate variables (e.g., mean, maximum and minimum precipitation and temperature), in geomorphological variables (e.g. altitude, slope, aspect) and in land use variables (e.g. forest, shrublands). We visually selected covariates with clear positive or negative relationships with Sorensen indices and then chose a subset of covariates with low pairwise correlations $(<0.27)$.

As neutral covariates, we selected the network distance and flow connection. The concept of distance deserves some considerations. In terrestrial ecosystems, scientists usually measure the distances between communities using the Euclidean distance which is the straight line distance between two sites. However, in riverine ecosystems habitats, the Euclidean distance does not adequately account for the spatial configuration, connectivity, directionality and relative location of the sites in the river network ${ }^{22,33}$. An alternative is to measure the network distance, which is the distance between two sites along the river network. However, there is a caveat concerning the use of network distances. Two geographically close sites can be separated by a large network distance. If we look at Fig. 2 we see that sites A and B are relatively close as judged by the Euclidean distance but very far when considering the network distance. Given that riparian plant species' seeds can be dispersed by several means other than water (e.g., wind and animals) we can expect sites A and B to share a higher proportion of species than we would expect if we just considered the network distance. In order to isolate the effect of network distance on community similarity we excluded pairs of sites for which the ratio between the network distance and the Euclidean distance was equal or lower than 2. As such, the number of unique site pairs was reduced from 7846 to 3857. In addition to network distances, we also calculated the covariate flow connection, which is a binary variable that denotes whether two vegetation samples are connected by flow (1) or not (0). We calculated the network distance and flow connection with the R package "igraph 1.26" 34 and "shp2graph 0-5" 35 . We used river network from CCM River and Catchment Database Version 2.0 ${ }^{36}$.

As niche-based covariates we selected two variables, differences in annual precipitation and differences in Strahler order. Annual precipitation is a good proxy for relative humidity, hydrological regime, and potential evapotranspiration. These are good predictors for riparian plant communities' composition in Mediterranean environments $^{20}$. We calculated the absolute value of the difference in mean annual precipitation between two sites using data between 1960 and $1990^{37}$. We also included the Strahler order, a measure of network position and stream size. We consider the Strahler order a niche variable because streams with lower Strahler order tend to be shallower, narrower, and closer to the river source. In comparison, streams with higher Strahler order are deeper, broader, and closer to the river mouth, thus denoting several environmental characteristics of the riverine 


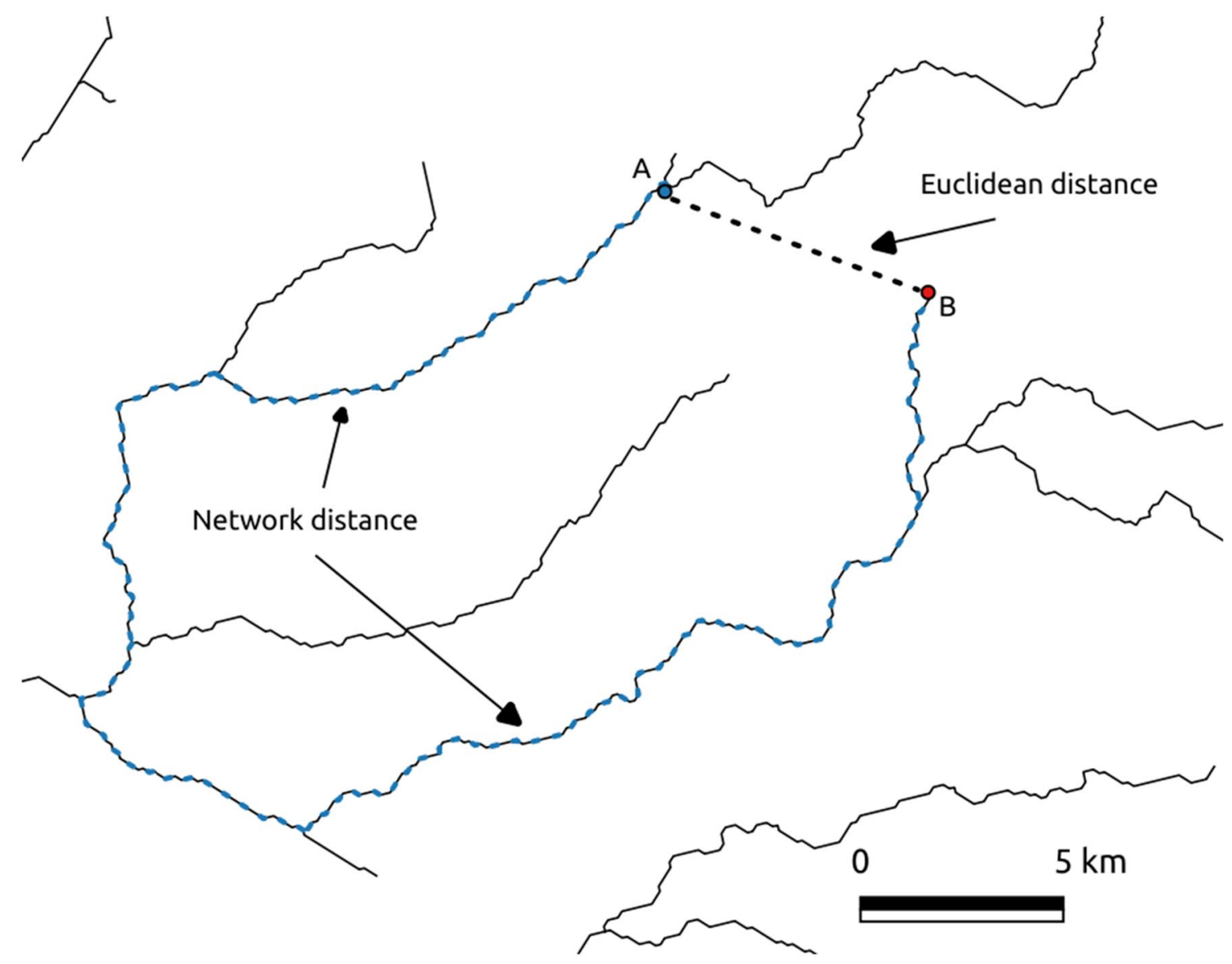

Figure 2. This figure shows two riparian vegetation samples, $A$ and $B$ (blue and red dot) that are separated by a large network distance (dashed blue line) and by a small Euclidean distance (dashed black line).

ecosystem ${ }^{21,38}$. We calculated the absolute value of the difference in Strahler order using Strahler order values provided by the CCM River and Catchment Database Version $2.0^{36}$.

Data analysis. To analyse the data, we used a hierarchical Bayesian approach ${ }^{39}$. We begin by introducing the model's formula and then provide a more detailed explanation.

Likelihood.

Sorensen index $\sim$ Beta distribution $(\mu, \kappa)$.

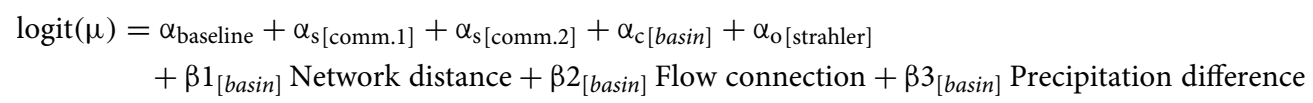

Priors.

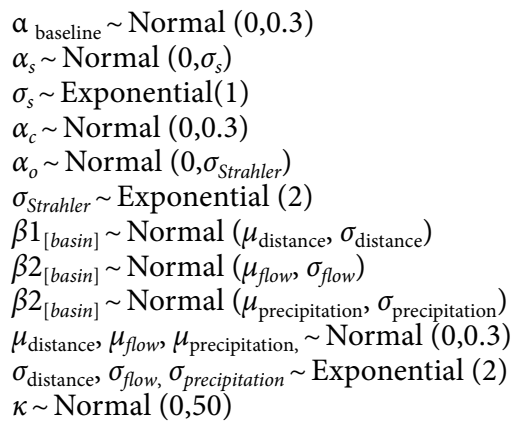


We modelled Sorensen indices with a Beta distribution using the mean $(\mu)$ and sample size $(\kappa)$ parameterisation ${ }^{40}$ because similarity indices range between 0 and 1 . To make sure location parameter $\mu$ is bounded between 0 and 1 we modelled the logit of $\mu$ in a linear model of the covariates. The terms $\alpha_{s[c o m m .1]}$ and $\alpha_{s[c o m m .2]}$ are additive varying intercepts that incorporate the dependence resulting from having Sorensen indices calculated with the same sample ${ }^{39}$. By definition, each Sorensen index is paired comparison between two ecological communities, therefore we need to explicitly model the contributions of both communities that comprise each Sorensen index observation. The term $\alpha_{c}$ is a varying intercept with 11 levels representing each river basin's independent contribution. To capture the influence of the Strahler order difference, we introduced a varying intercept $\alpha_{o}$ with seven levels representing the independent contribution of Strahler order difference. This approach allows the model to capture expected nonlinear correlations between the logit $(\mu)$ and Strahler order differences. Flow connection, network distance, and precipitation differences were added as regular covariates to the model. We transformed both covariates to improve model fit and identifiability and to improve run time. Rather than rescaling the covariates by subtracting the mean and dividing by the standard deviation we decided to use values determined by our domain expertise, which improves the interpretability and generalizability of the resulting inferences. We transformed network distance values by subtracting $100 \mathrm{~km}$ to observed values and divided the resulting value by 100 . We believe that given the study area's characteristics $100 \mathrm{~km}$ is a reasonable threshold beyond which we can expect to find changes in community composition due to ecological drift. Therefore, a slope of, for instance, -0.10 means that an increase of $1 \mathrm{~km}$ in the network distance beyond a baseline of $100 \mathrm{~km}$ will decrease Sorensen indices by -0.10 . Precipitation difference values were logtransformed with $\log (\mathrm{x}+1)$. We used a log-transformation because the distribution of the values was skewed and presented a second maximum for larger values (Appendix 1-Section X). Afterwards, we subtracted 5.71 $(\log (300 \mathrm{~mm}+1)=5.71)$ and divided the resulting value by 5.71 . We selected $300 \mathrm{~mm}$ because it is the average minimum precipitation value for Mediterranean climates. A slope of -0.1 indicates that if the precipitation difference increases by $1 \mathrm{~mm}$ beyond $300 \mathrm{~mm}$, the Sorensen index will change by -0.10 . The slopes for these three covariates were sampled from a hierarchical distribution (i.e., hyper prior) that generates parameters for all eleven river basins. Slope estimates obtained in this fashion are more precise at the river basin level and usually more robust to extreme observations ${ }^{41}$. We interpreted the posterior distribution of $\mu_{\text {distance, }}, \mu_{\text {flow }}$, and $\mu_{\text {precipitation }}$ as the average effect of the covariate on Sorensen indices if we were to go out into the field to gather vegetation samples from additional river basins.

We used a weakly informative prior following the work by Rodríguez-González et al. ${ }^{42}$. We assumed that a high number of samples would share between 25 and $65 \%$ of the species, but also assigned a relatively high probability to lower and higher values. Concerning the covariates, we chose normal distributions for the hyper priors $\mu_{\beta}$ of the slope parameters $\beta$ with mean zero and a standard deviation of 0.3 . These prior choices are also weakly informative allowing for both positive and negative relationships between Sorensen indices and the four covariates. To verify our prior choices we inspected 1000 Sorensen similarity index distributions.

To check that our model captures the data's relevant structure, we compared the observed distribution of the Sorensen indices with the posterior distribution of Sorensen indices. Specifically, we (1) plotted the differences between the posterior distribution and the observed Sorensen indices (i.e., error distributions) conditional on covariates and (2) plotted the posterior distribution of Sorensen indices against the covariates. We checked for systematic deviations that indicated structure in the data that our model was unable to capture. We assessed the importance of the covariates by checking if the corresponding parameter's $95 \%$ credibility interval included zero and by evaluating the parameter's magnitude. We chose $95 \%$ because it is a standard threshold in both frequentist and Bayesian statistics. However, we do not base our conclusions concerning the importance of the covariate solely on the credibility interval containing zero.

We used the software Stan via the R package "rstan" 43 and run the models with four independent Markov chains with 1000 warmup iterations and 2000 sampling iterations. To check if our Markov chains were stationary and enabled reasonable posterior expectation value estimators, we performed both qualitative and quantitative diagnostics. In addition, to spot-checking traceplots, we checked that the split potential scale reduction factor (Rhat) was consistent with 1 for all functions of interest and verified that there were no divergent transitions or Markov chains that saturated the maximum tree depth.

Throughout the manuscript, we use the term "retrodictive" instead of "predictive" to refer to the process of comparing predicted results with observed data ${ }^{44}$.

\section{Results}

Prior predictive checks. We obtained 1000 simulations of Sorensen indices from the prior model and observed that most distributions present a high probability mass between 25 and $65 \%$ of the species (Fig. 3 left) which is in accordance with our goal.

Model validation. The chains were stationary and well mixing with Rhat values of $\sim 1$. No iterations ended with divergences or saturated the maximum tree depth. The posterior retrodictive distribution of Sorensen indices closely matched the observed distribution of Sorensen indices except for values below 0.05 , which are slightly overestimated, and for values above 0.62 , which are slightly underestimated. We found no systematic deviations between our data and model (Fig. 3 and Appendix 1).

Neutral variables. Network distance was negatively associated with Sorensen similarity indices, with mean slope estimates ranging between -0.16 for the Douro and -0.75 for the Cávado and Vouga basins. In Mira and Minho basins, a small part of the $95 \%$ credibility intervals crosses zero, which means there is a small probability that the slopes are zero or slightly positive (Fig. 4 ). The estimate for $\mu_{\text {distance }}$ was -0.37 with a $95 \%$ credibility 

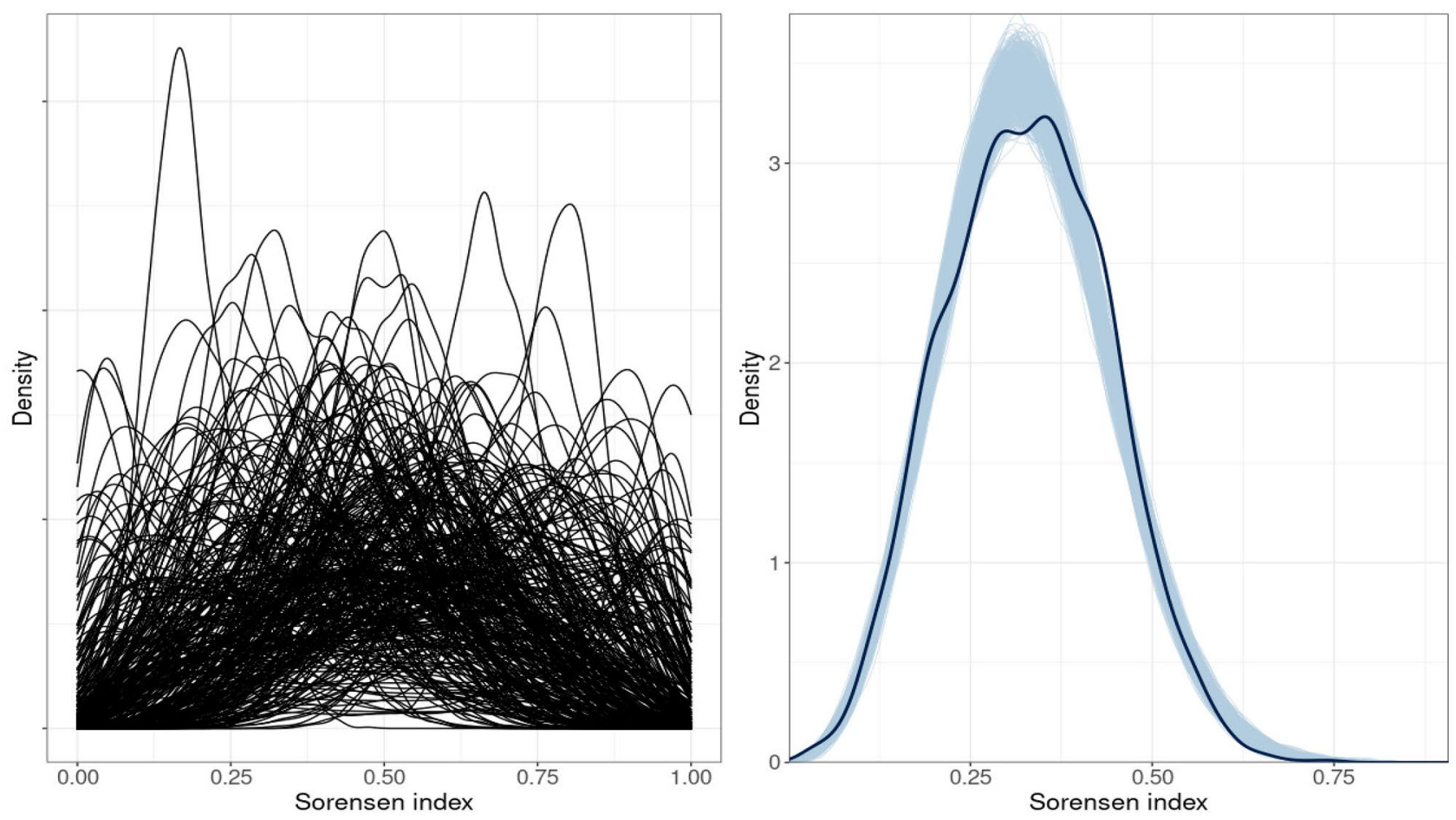

Figure 3. Density plots showing prior predictive distribution (left) and the observed. distribution of Sorensen indices (thick line) against 1000 posterior distributions (thin lines) (right).

interval $[-0.55,-0.19]$. We can interpret this results as follows: beyond a threshold distance of $100 \mathrm{~km}$, if the network distance increases by $1 \mathrm{~km}$, the Sorensen index decreases by $37 \%$.

Vegetation samples connected by streamflow seem to be slightly more similar than those that are not. Mean slope estimates were relatively small but predominantly positive except for Mondego basin's slope, whose estimate was very close to zero. For the remaining basins, mean estimates ranged between 0.02 and 0.06 (Fig. 4). All $95 \%$ credibility intervals crossed 0 , which means that weakly negative contributions are also consistent with the data. The mean estimate for $\mu_{\text {flow }}$ is $0.04[-0.02,0.10]$, which suggests that when all covariates remain constant the Sorensen index increases by $4 \%$ when two vegetation samples are connected. However, decreases of $2 \%$ or increases of $10 \%$ are also consistent with the data, but less likely.

Niche-based variables. Strahler order difference had a negative association with community similarity. Sorensen indices seem to decrease linearly when Strahler order differences change between 0 and 4 , but this decrease is steeper when Strahler order increases to 5 and mainly to 6 (Fig. 4). For instance, when two vegetation samples have a Strahler order difference of 6 , Sorensen indices will on average be $98 \%$ smaller.

Higher differences in precipitation are associated with lower levels of community similarity. The mean estimates for precipitation difference slopes were negative, with mean values ranging between -0.53 and 0.12 (Fig. 4). However, in six out of eleven basins, credibility intervals crossed zero, indicating the effect could also be weakly positive with varying degrees of probability. For instance, over $30 \%$ of Mira's basin parameter distribution is on the right side of zero. The estimate for $\mu_{\text {precipitation }}$ was $-0.32[-0.55,-0.19]$ which means that when precipitation difference increases by $1 \mathrm{~mm}$ beyond a threshold of $300 \mathrm{~mm}$, Sorensen indices decrease on average by $32 \%$.

A slope of -0.1 indicates that if the precipitation difference increases by $1 \mathrm{~mm}$ beyond $300 \mathrm{~mm}$ $(\log (300 \mathrm{~mm}+1)=5.71)$, the Sorensen index will change by -0.10 .

\section{Discussion}

In this work, we analysed the influence of neutral and niche-based factors on the distance decay of community similarity (DDCS) in riparian plant communities of eleven river basins in continental Portugal. We considered two neutral covariates, network distance and flow connection and two niche-based covariates, precipitation difference, and Strahler order difference.

Network distance was positively associated with lower community similarity. The ecological neutral theory argues the DDCS is caused by ecological drift, which consists of random extinctions, species replacement ${ }^{12,45}$, and by random dispersal coupled with dispersal limitations ${ }^{46}$. As distances increase, the probability of successful seed dispersal decrease ${ }^{47-49}$, which can explain why community similarity decreases with distance. Still, we cannot rule out the possibility that an unmeasured covariate correlated with network distance may have caused this result. For instance, drought-related habitat fragmentation could hinder seed dispersal ${ }^{50}$ and cause identical reductions in community similarity. However, we believe that the covariate precipitation difference already captures drought-related effects. 

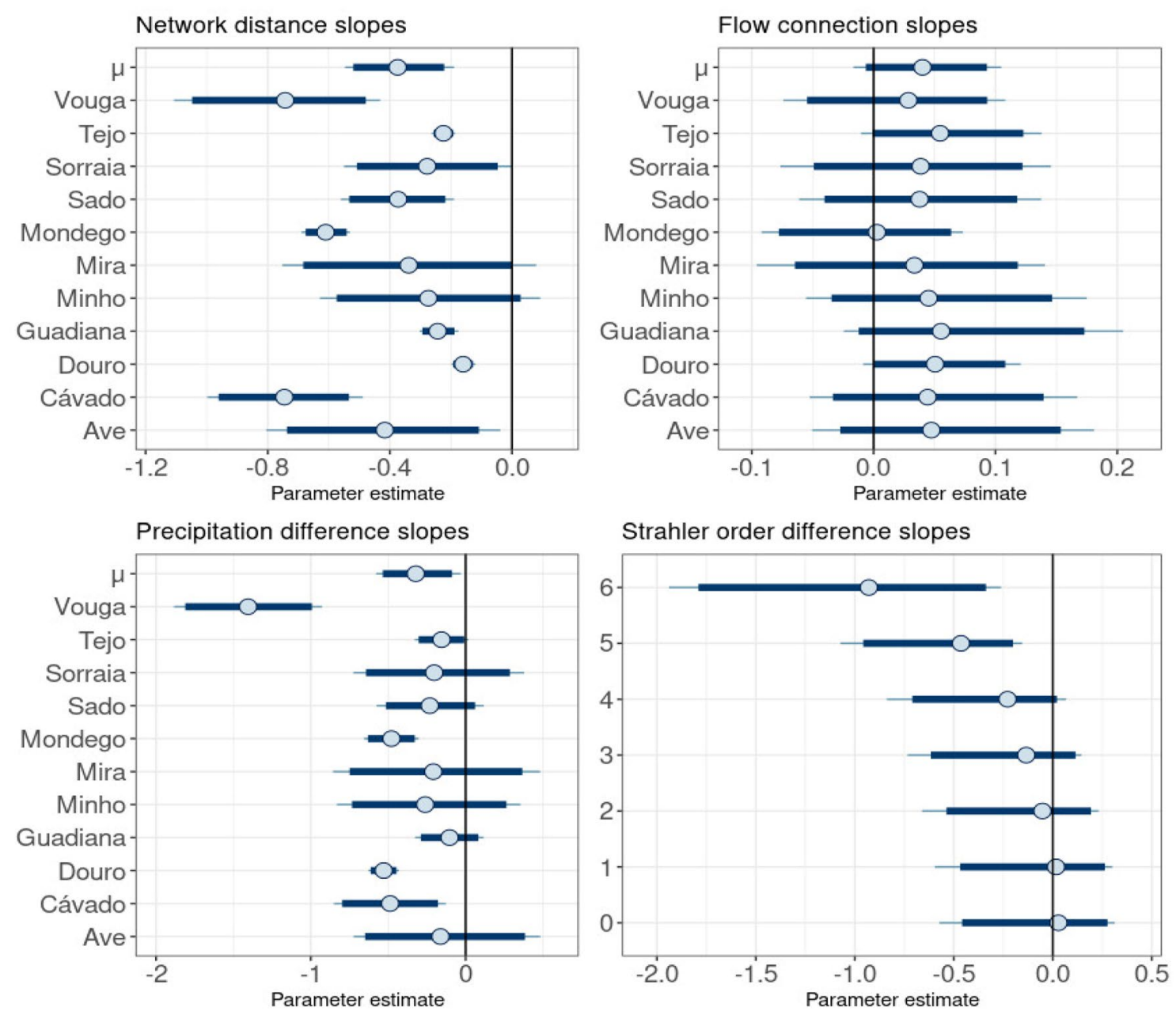

Figure 4. Posterior estimates for the parameters corresponding to the network distance, flow connection, precipitation difference and Strahler order difference. The parameter $\mu$ is the mean of the normal distribution where slopes are sampled. Dark blue lines represent $95 \%$ credibility intervals. The thin light blue line represents the complete distribution of the parameters. The dot represents the marginal posterior mean.

Sorensen indices from vegetation samples that are connected by water are $4 \%$ higher than those that are not. Indeed, flow connectivity is responsible for high level of diversity in fluvial ecosystems ${ }^{51}$. Most riparian plant species have the ability to disperse seeds through water ${ }^{52}$, explaining why communities connected by streamflow share a higher number of species, and the pattern of increased richness in a downstream direction ${ }^{53-55}$. This result may be also caused by an association between streamflow and katabatic winds. Air masses that are thermally forced from higher to lower altitudes usually travel along river network ${ }^{56}$. These air masses can transport seeds and pollinators along with river networks, thus increasing community similarity ${ }^{57,58}$. Another possibility is that pollinators may be more prone to move along river corridors following their foraging preferences ${ }^{59}$, thus contributing to higher community similarities.

Community similarity was higher between vegetation samples experiencing lower differences in precipitation. Continental Portugal exhibits a high precipitation gradient. This spatial and temporal variability in precipitation results in some regions/periods of the year experiencing frequent droughts during the summer and others experiencing intense floods during the winter ${ }^{20}$. Plant communities have thus adapted to these conditions. In drier areas, riparian ecosystems harbor a higher number of terrestrial plants and proportionally fewer strictly riparian or aquatic species ${ }^{60}$. In wetter regions, the prevalence of species adapted to waterlogged and frequently flooded is considerably higher ${ }^{60}$. This community composition pattern may cause a negative relationship between community similarity and precipitation difference.

Overall, community similarity decreases with increasing Strahler order differences. This result suggests that riparian plant communities located closer to the river's source (lower Strahler order) tend to differ from those closest to the river's mouth (higher Strahler order), even after accounting for network distance. Moreover, this difference increases with increasing separation in river networks, particularly when Strahler order differences increase to five and six. Differences in community composition may be explained by differences in environmental features upstream and downstream ${ }^{61}$ such as elevation, channel gradient, valley constraints, geomorphic processes, and substrate diversity ${ }^{20,21,38}$. An alternative explanation for this result are confluence effects ${ }^{62}$. When two rivers meet, water and sediment influx changes affect channel and floodplain morphology and alter the composition of riparian plant communities, which could produce similar results to those we observed. 
In summary, our model results suggest that community similarity changes are associated with both environmental and neutral factors. Both niche-based and neutral variables were associated with non-null changes in Sorensen indices. Network distances and Strahler order differences had the largest effect sizes, followed by precipitation difference and flow connection. Overall, the results seem to be consistent with the continuum hypothesis that states that niche and neutral factors are at opposite ends of a continuum ${ }^{14}$. The results from this study contribute to improving our knowledge of the processes that shape riparian ecosystems and underline the importance of considering both environmental and neutral factors when analysing changes in community composition.

Received: 9 June 2021; Accepted: 22 October 2021

Published online: 04 November 2021

\section{References}

1. Nekola, J. C. \& White, P. S. The distance decay of similarity in biogeography and ecology. J. Biogeogr. 26, 867-878 (1999).

2. Soininen, J., McDonald, R. \& Hillebrand, H. The distance decay of similarity in ecological communities. Ecography 30, 3-12 (2007).

3. Whittaker, R. H. Communities and Ecosystems (MacMillan Publishing, 1975).

4. Pulliam, H. R. On the relationship between niche and distribution. Ecol. Lett. 3, 349-361 (2000).

5. Pulliam, H. Sources, sinks, and population regulation. Am. Nat. 132, 652-661 (1988).

6. Hanski, I. \& Gilpin, M. Metapopulation dynamics: Brief history and conceptual domain. Biol. J. Linn. Soc. 42, 3-16 (1991).

7. MacArthur, R. H. \& Wilson, E. O. The Theory of Island Biogeography (Princeton University Press, 2001).

8. Tuomisto, H. \& Ruokolainen, K. Analyzing or explaining beta diversity? Understanding the targets of different methods of analysis. Ecology 87, 2697-2708 (2006).

9. Astorga, A. et al. Distance decay of similarity in freshwater communities: Do macro- and microorganisms follow the same rules?: Decay of similarity in freshwater communities. Glob. Ecol. Biogeogr. 21, 365-375 (2012).

10. Leibold, M. A. et al. The metacommunity concept: A framework for multi-scale community ecology. Ecol. Lett. 7, 601-613 (2004).

11. Nekola, J. C. \& Brown, J. H. The wealth of species: Ecological communities, complex systems and the legacy of Frank Preston. Ecol. Lett. 10, 188-196 (2007).

12. Hubbell, S. The Unified Neutral Theory of Biodiversity and Biogeography (MPB-32) (Princeton University Press, 2001).

13. Fodelianakis, S., Valenzuela-Cuevas, A., Barozzi, A. \& Daffonchio, D. Direct quantification of ecological drift at the population level in synthetic bacterial communities. ISME J. https://doi.org/10.1038/s41396-020-00754-4 (2020).

14. Gravel, D., Canham, C. D., Beaudet, M. \& Messier, C. Reconciling niche and neutrality: The continuum hypothesis: Reconciling niche and neutrality. Ecol. Lett. 9, 399-409 (2006).

15. Legendre, P., Borcard, D. \& Peres-Neto, P. R. Analyzing beta diversity: Partitioning the spatial variation of community composition data. Ecol. Monogr. 75, 435-450 (2005).

16. Wilson, K. A., Cabeza, M. \& Klein, C. J. Fundamental concepts of spatial conservation prioritization. In Spatial Conservation Prioritization: Quantitative Methods \& Computational Tools (eds Moilanen, A. et al.) 16-27 (Oxford University Press, 2009).

17. Morlon, H. et al. A general framework for the distance-decay of similarity in ecological communities. Ecol. Lett. 11, 904-917 (2008).

18. Tuomisto, H. Dispersal, environment, and floristic variation of western Amazonian forests. Science 299, 241-244 (2003).

19. Gómez-Rodríguez, C. \& Baselga, A. Variation among European beetle taxa in patterns of distance decay of similarity suggests a major role of dispersal processes. Ecography 41, 1825-1834 (2018).

20. Stella, J. C., Rodríguez-González, P. M., Dufour, S. \& Bendix, J. Riparian vegetation research in Mediterranean-climate regions: Common patterns, ecological processes, and considerations for management. Hydrobiologia 719(1), 291-315 (2013).

21. Vannote, R. L., Minshall, G. W., Cummins, K. W., Sedell, J. R. \& Cushing, C. E. The river continuum concept. Can. J. Fish. Aquat. Sci. 37, 130-137 (1980).

22. Rouquette, J. R. et al. Species turnover and geographic distance in an urban river network. Divers. Distrib. 19, 1429-1439 (2013).

23. Kuglerová, L., Jansson, R., Sponseller, R. A., Laudon, H. \& Malm-Renöfält, B. Local and regional processes determine plant species richness in a river-network metacommunity. Ecology 96, 381-391 (2015).

24. Zhang, Z., Gao, J. \& Cai, Y. The effects of environmental factors and geographic distance on species turnover in an agriculturally dominated river network. Environ. Monit. Assess. 191, 201 (2019).

25. Jost, L., Chao, A. \& Chazdon, R. Compositional similarity and beta diversity. In Biological Diversity: Frontiers in Measurement and Assessment (eds Magurran, A. \& McGill, B.) 66-84 (Oxford University Press, 2011).

26. Olson, D. M. et al. Terrestrial ecoregions of the world: A new map of life on earth. Bioscience 51, 933 (2001).

27. Miranda, P., Coelho, F., Tomé, A. \& Valente, M. Climate Change in Portugal. Scenarios, Impacts and Adaptation Measures-SIAM Project (Gradiva, 2002).

28. CIS-WFD. River and lakes-Typology, reference conditions and classification systems, Common Implementation Strategy for the Water Framework Directive (2000/60/EC), Guidance document $n^{\circ} 10.94$ (2003).

29. INAG. Manual para a avaliação biológica da qualidade da água em sistemas fluviais segundo a DQA-Protocolo de amostragem e análise para os macrófitos (2008).

30. Agência Portuguesa do Ambiente. Plano de Gestão da Região Hidrográfica do Tejo, Relatório técnico, Versão Extensa Parte 2-Caracterização e Diagnóstico da Região Hidrográfica. (2012).

31. Oksanen, J. et al. vegan: Community Ecology Package -Version 2.7-7. https://CRAN.R-project.org/package=vegan (2021).

32. R Core Team. R: A Language and Environment for Statistical Computing (R Foundation for Statistical Computing, 2021).

33. Peterson, E. E., Theobald, D. M. \& Ver Hoef, J. M. Geostatistical modelling on stream networks: Developing valid covariance matrices based on hydrologic distance and stream flow. Freshw. Biol. 52, 267-279 (2007).

34. Csardi, G. \& Nepusz, T. The Igraph software package for complex network research. InterJournal Complex Syst. 1695, 1-9 (2005).

35. Lu, B., Sun, H., Harris, P., Xu, M. \& Charlton, M. Shp2graph: Tools to convert a spatial network into an Igraph graph in R. ISPRS Int. J. Geo-Inf. 7, 293 (2018).

36. Vogt, J. \& Foisneau, S. CCM River and Catchment Database-Version 2.0 Analysis Tools. (2007).

37. Monteiro-Henriques, T. et al. Bioclimatological mapping tackling uncertainty propagation: Application to mainland Portugal. Int. J. Climatol. 36, 400-411 (2016).

38. Ward, J. V. \& Stanford, J. A. The serial discontinuity concept: Extending the model to floodplain rivers. Regul. Rivers Res. Manag. 10, 159-168 (1995).

39. Dias, F. S., Betancourt, M., Rodríguez-González, P. M. \& Borda-de-Água, L. A Bayesian Approach for Analysing Pairwise Comparisons: A Case Study Using Species Composition Similarity (2021) https://doi.org/10.32942/osf.io/sn5jr.

40. Stan Development Team. Stan Functions Reference Version 2.25. (2020).

41. McElreath, R. Statistical Rethinking: A Bayesian Course with Examples in R and Stan (Chapman and Hall/CRC, 2020). 
42. Rodríguez-González, P. M., Ferreira, M. T., Albuquerque, A., Santo, D. E. \& Rego, P. R. Spatial variation of wetland woods in the latitudinal transition to arid regions: A multiscale approach. J. Biogeogr. 35, 1498-1511 (2008).

43. Stan Development Team. RStan: the R interface to Stan Version 2.21. https://github.com/stan-dev/rstan/wiki/RStan-Getting-Start ed (2020).

44. Betancourt, M. Hierarchical Modeling (2020).

45. Muneepeerakul, R., Weitz, J. S., Levin, S. A., Rinaldo, A. \& Rodriguez-Iturbe, I. A neutral metapopulation model of biodiversity in river networks. J. Theor. Biol. 245, 351-363 (2007).

46. Thompson, R. \& Townsend, C. A truce with neutral theory: Local deterministic factors, species traits and dispersal limitation together determine patterns of diversity in stream invertebrates: Neutral theory and local determinism. J. Anim. Ecol. 75, 476-484 (2006).

47. Steinitz, O., Heller, J., Tsoar, A., Rotem, D. \& Kadmon, R. Environment, dispersal and patterns of species similarity. J. Biogeogr. 33, 1044-1054 (2006).

48. Nilsson, C., Brown, R. L., Jansson, R. \& Merritt, D. M. The role of hydrochory in structuring riparian and wetland vegetation. Biol. Rev. Camb. Philos. Soc. 85, 837-858 (2010).

49. Gelmi-Candusso, T. A. et al. Estimating seed dispersal distance: A comparison of methods using animal movement and plant genetic data on two primate-dispersed Neotropical plant species. Ecol. Evol. 9, 8965-8977 (2019).

50. Rodríguez-González, P. M. et al. A spatial stream-network approach assists in managing the remnant genetic diversity of riparian forests. Sci. Rep. 9, 6741 (2019).

51. Ward, J. V., Tockner, K., Arscott, D. B. \& Claret, C. Riverine landscape diversity. Freshw. Biol. 47, 517-539 (2002).

52. Fraaije, R. G. A. et al. Spatial patterns of water-dispersed seed deposition along stream riparian gradients. PLoS ONE 12, e0185247 (2017).

53. Bendix, J. Flood disturbance and the distribution of riparian species diversity. Geogr. Rev. 87, 468-483 (1997).

54. Kuglerová, L., Dynesius, M., Laudon, H. \& Jansson, R. Relationships between plant assemblages and water flow across a boreal forest landscape: A comparison of liverworts, mosses, and vascular plants. Ecosystems 19, 170-184 (2016).

55. Wubs, E. R. J. et al. Going against the flow: A case for upstream dispersal and detection of uncommon dispersal events. Freshw. Biol. 61, 580-595 (2016).

56. Carrera, M., Gyakum, J. \& Lin, C. Observational study of wind channeling within the St. Lawrence river valley. J. Appl. Meteorol. Climatol. 48, 2341-2361 (2009).

57. Kuparinen, A., Katul, G., Nathan, R. \& Schurr, F. M. Increases in air temperature can promote wind-driven dispersal and spread of plants. Proc. R. Soc. B Biol. Sci. 276, 3081-3087 (2009).

58. Soomers, H. et al. Wind and water dispersal of wetland plants across fragmented landscapes. Ecosystems 16, 434-451 (2013).

59. Jones, K. N. Analysis of pollinator foraging: Tests for non-random behaviour. Funct. Ecol. 11, 255-259 (1997).

60. Ferreira, M. T. \& Aguiar, F. Riparian and aquatic vegetation in Mediterranean-type streams (western Iberia). Limnetica 25, 411-424 (2005).

61. Petts, G. E. \& Amoros, C. Fluvial hydrosystems: a management perspective. In The Fluvial Hydrosystems (eds Petts, G. E. \& Amoros, C.) 263-278 (Springer Netherlands, 1996) https://doi.org/10.1007/978-94-009-1491-9_12.

62. Benda, L. et al. The network dynamics hypothesis: How channel networks structure riverine habitats. Bioscience 54, 413-427 (2004).

63. QGIS Development Team. QGIS Geographic Information System-Version 3.20.3. (2021).

\section{Acknowledgements}

FD, LBA and PMRG were financed by FEDER Funds through the Operational Competitiveness Factors Program - COMPETE and by National Funds through Fundação para a Ciência e a Tecnologia (FCT). FD through project PTDC/BIA-ECO/28729/2017 - POCI-01-0145-FEDER-028729, LBA under the Norma Transitória - L57/2016/ CP1440/CT0022, and PMRG through CEEC Individual Programme (2020.03356.CEECIND). Forest Research Centre is a research unit funded by FCT (UIDB/00239/2020).

\section{Author contributions}

F.S.D., M.B., P.M.R. and L.B.D.A. conceived the paper and designed methodology. PMR collected the data. F.S.D. and M.B. analysed the data. F.S.D. led the writing of the manuscript. All authors contributed critically to the drafts and gave final approval for publication.

\section{Competing interests}

The authors declare no competing interests.

\section{Additional information}

Supplementary Information The online version contains supplementary material available at https://doi.org/ 10.1038/s41598-021-01149-x.

Correspondence and requests for materials should be addressed to F.S.D.

Reprints and permissions information is available at www.nature.com/reprints.

Publisher's note Springer Nature remains neutral with regard to jurisdictional claims in published maps and institutional affiliations.

Open Access This article is licensed under a Creative Commons Attribution 4.0 International License, which permits use, sharing, adaptation, distribution and reproduction in any medium or format, as long as you give appropriate credit to the original author(s) and the source, provide a link to the Creative Commons licence, and indicate if changes were made. The images or other third party material in this article are included in the article's Creative Commons licence, unless indicated otherwise in a credit line to the material. If material is not included in the article's Creative Commons licence and your intended use is not permitted by statutory regulation or exceeds the permitted use, you will need to obtain permission directly from the copyright holder. To view a copy of this licence, visit http://creativecommons.org/licenses/by/4.0/.

(C) The Author(s) 2021 